\title{
Seasonal changes and population dynamics of the ctenophore Mnemiopsis leidyi after its first year of invasion in the Kiel Fjord, Western Baltic Sea
}

\author{
Jamileh Javidpour · Juan Carlos Molinero • \\ Jesco Peschutter · Ulrich Sommer
}

Received: 15 April 2008/Accepted: 5 June 2008/Published online: 25 June 2008

(C) The Author(s) 2008

\begin{abstract}
We analyzed the seasonal variations of the ctenophore Mnemiopsis leidyi weekly collected since its first record in the western Baltic Sea in October 2006. The distribution pattern together with the seasonal dynamics and population outbreaks in late summer 2007 indicate recent successfully establishment of M. leidyi in this area. Seasonal changes showed two periods of high reproductive activity characterized by a population structure dominated by small size classes, followed by an increase of larger ones. These results further revealed that the bulk of the population remains in deep layers during the periods of low population density, whereas it appeared situated in upper layers during the proliferation of the species. We further emphasized the strength of the population outbreaks, which can reach abundances $>10$-fold higher in time periods shorter than a week. The predatory impact this species may
\end{abstract}

J. Javidpour $(\bowtie) \cdot$ J. C. Molinero · J. Peschutter .

U. Sommer

Marine Ecology, Leibniz-Institute of Marine Sciences,

Duesternbrooker Weg 20, 24105 Kiel, Germany

e-mail: jjavid@ifm-geomar.de

J. C. Molinero

e-mail: jcmolinero@ifm-geomar.de

J. Peschutter

e-mail: jpeschutter@ifm-geomar.de

U. Sommer

e-mail: usommer@ifm-geomar.de have in pelagic ecosystems warns on the importance of its recent range of expansion.

Keywords Biological invasions - Ctenophores · Mnemiopsis leidyi Population structure - Baltic Sea

\section{Introduction}

Biological invasions are currently one of the leading threats to the diversity of aquatic ecosystems worldwide. Through competition, predation, and habitat alteration, invaders can radically change both the species composition and functioning of invaded ecosystems (Levine 2008). Concerns of biological invasions in marine ecosystems relate to the serious ecological and economical menace, which lead to biodiversity loss, ecosystem unbalancing, fishery and tourism impairment. Furthermore, in the ecological theory framework, biological invasions are of great interest since they represent unique natural experiments for understanding the structure and functioning of ecological communities (Occhipinti-Ambrogi and Savini 2003).

The Baltic Sea is one of the largest brackish water bodies on earth and possibly one of the most exposed European areas to global warming (IPCC 2007). In addition, the 16 million people living in immediate vicinity of the coast and the 85 million within the catchment's area make the Baltic Sea highly vulnerable to human-induced ecological impacts (Leppakoski 
et al. 2002). In the last century, the Baltic Sea has undergone drastic perturbations related to ecosystemwide structural changes, i.e. a shift from a system with seals to cods as top-predators followed by a shift to an eutrophic sea, and during the recent decades a shift from cod to clupeids as dominant fish (Alheit et al. 2005; Österblom et al. 2007). Hence, human induced impacts (i.e. overfishing, eutrophication) as well as natural factors (broad salinity-temperature gradients), made the Baltic Sea an unstable ecosystem, which could be extremely favorable for invasion of nonindigenous species (Paavola et al. 2005). This may explain the large number of alien species reported in the Baltic Sea during the last two centuries $(\sim 100$ species; Leppakoski et al. 2002). Consequently, the Baltic Sea represents an important node in global aquatic invasive species (Gollasch and Leppäkoski 2007).

One of the most dramatic and serious effects of alien species in European seas so far has been the introduction of Mnemiopsis leidyi in the Black Sea, where it showed an explosive outbreak and expanded into the Azov, Marmara, and Caspian Seas (Shiganova 1998). M. leidyi is widely recognized as a harmful invader and ranked among the world's 100 worst invasive species (http://www.issg.org/). It became particularly infamous for causing major ecological and economic damage to the Black Sea ecosystem after its introduction in the 1980s (Shiganova et al. 2001; Stone 2005). Its presence in northern European waters has been reported in some Netherlands estuaries where it probably existed already since several years (Faasse and Bayha 2006), and recent records indicate a progressive eastward spread (Janas and Zgrundo 2007; Javidpour et al. 2006; Kube et al. 2007; Lehtiniemi et al. 2007). In the southwest Baltic Sea, the first record of M. leidyi was October 2006 (Javidpour et al. 2006). Concerns about this invasion have led to the systematic monitoring to track population density variations of this species and the physical factors that favor its development.

The strong ecological impact of M. leidyi on marine food webs stems from both the direct feeding on fish larvae and eggs and resource competition with zooplanktivourus fish due to its voracious feeding on mesozooplankton. Recent investigations, however, reveal that cause and effect relationships between M. leidyi and fish are controversial since pelagic fish stocks were already declining prior to the advent of
M. leidyi in the Black Sea (Bilio and Niermann 2004; Oguz and Gilbert 2007). While a potential effect on the ecosystem structure of the pelagic Baltic ecosystem including impacts on fisheries remains an open question, a prior understanding of the seasonal variations and population dynamics of $M$. leidyi is required to evaluate and potentially prevent any possible effect of this species in the marine ecosystem of the Baltic Sea. Here we provide the first data on the annual cycle, seasonal changes and population dynamics of M. leidyi in the southwestern Baltic Sea after its first occurrence, and discuss the possible mechanisms underlying its establishment in the Baltic ecosystem.

\section{Methods}

The study area

The sampling station is located in the inner part of Kiel Fjord (south-west Baltic Sea, Fig. 1), which with a mean depth of about $13 \mathrm{~m}$, constitutes a small extension of the Kiel Bight in the Belt Sea. The Belt Sea area is a transition zone between the higher saline water masses from the Kattegat and brackish waters from the central Baltic Sea, separated by the Belt Sea front. Mainly under the influence of the wind, this frontal zone moves back and forth through the Great Belt and Fehmarn Belt. Salinity changes in the Kiel Bight directly influence the salinity in the Kiel Fjord by baroclinic exchange. Under strong wind conditions the Kiel Fjord can be completely flushed within a few days (Lehmann, personal communication).

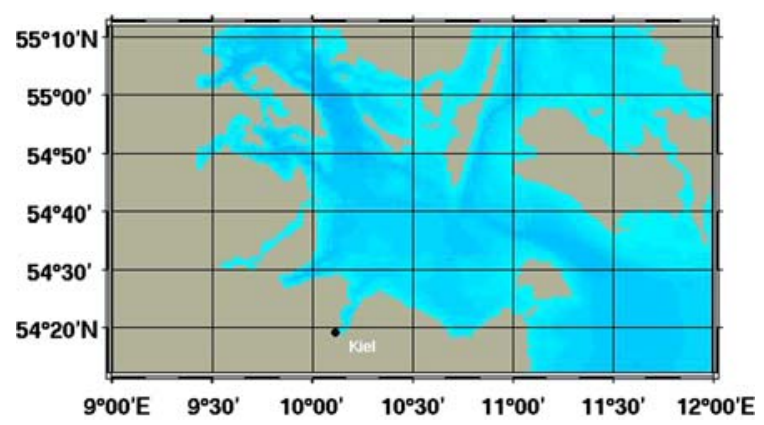

Fig. 1 Map of the Western Baltic Sea showing the location of the Kiel Fjord 
Sampling

Plankton sampling covered the period of October 2006 to December 2007 and was performed at weekly intervals during most of the year.

Microplankton composition and abundance was quantified from water samples taken with a free flow sampler at 0,8 and $18 \mathrm{~m}$ depth at a central station in the Kiel Fjord. These samples were merged to obtain an estimate of the microplankton composition in the entire water column. Samples were fixed by Lugol's iodine solution and analyzed under an inverse microscope later in the laboratory.

Mesozooplankton was sampled at the same station with a plankton net $(0.6 \mathrm{~m}$ diameter opening, $200 \mu \mathrm{m}$ mesh size) from integrated vertical tows of $18 \mathrm{~m}$ depth to the surface. Samples were preserved in 5\% buffered formaldehyde-seawater mixture for later quantification. All mesozooplankton in the samples were identified at least to genus level under a dissecting microscope. In addition, ichthyoplankton and scyphomedusae samples were collected with the same frequency using a paired bongo net (335 and $500 \mu \mathrm{m}$ mesh size, $0.6 \mathrm{~m}$ mouth diameter) towed for $5 \mathrm{~min}$ on depth-integrated oblique hauls from surface to $10 \mathrm{~m}$ depth. Filtered volumes were estimated using a flowmeter mounted in the mouth of each net (the volume filtered averaged $100 \mathrm{~m}^{3}$ ). Scyphomedusae (Aurelia aurita and Cyanea capillata) were counted from the $500 \mu \mathrm{m}$ net on board and ichthyoplankton (fish larvae and eggs) of $500 \mu \mathrm{m}$ net was preserved in a $4 \%$ buffered formaldehyde-seawater mixture for later quantification.

Samples of M. leidyi were taken with a WP2 net $(0.8 \mathrm{~m}$ net opening, $500 \mu \mathrm{m}$ mesh size) making four replicated vertical hauls from the bottom to the surface. From March 2007 onwards samples from two distinct depth strata (0-10 and 10-18 m) were taken with a closing system matched to the WP2 net at the same station. Samples were concentrated on a $0.5 \mathrm{~mm}$ sieve and individuals counted and measured alive immediately after sampling, since $M$. leidyi has been found to disintegrate in all types of fixation solutions (Javidpour, personal observation). Total length was measured to the nearest $0.1 \mathrm{~mm}$ on individuals with closed lobes. Temperature and salinity were measured at the $1 \mathrm{~m}$ interval of the whole water column at each sampling day.
Data analysis

Data were $\log _{10}$-transformed and then standardized at zero mean and unit variance. Environmental windows allowing high abundance of $M$. leidyi were identified by means of cumulative abundance distribution in the temperature and salinity ranges (Perry and Smith 1994; Paramo et al. 2003). Seasonal changes in the age structure were assessed by means of the ratio larval stages:adults. This allows identifying major periods of elevated reproductive activity of $M$. leidyi in the Kiel Fjord. In addition, the vertical distribution of $M$. leidyi was analyzed according to a vertical distribution parameter (VDP) (Huntley and Escritor 1991; Escribano and Hidalgo 2000).VDP was calculated as: $\mathrm{VDP}=\log \left(n_{1} / n_{2}\right)$, where $n_{1}$ is the mean abundance in the upper layer $(10 \mathrm{~m})$ and $n_{2}$ is the mean abundance in the deeper layer $(8 \mathrm{~m})$. The obtained time series was standardized at zero mean and unit variance (z-scores) and the chart of cumulative $z$-scores was used to identify the date of trend initiation in seasonal changes of vertical distribution of M. leidyi.

\section{Results}

Hydrographical features

The seasonal development of temperature and salinity is displayed in Fig. 2. During the study period, high salinity of 20-22 PSU characterized autumn and winter periods. In spring, salinity dropped to a minimum value of $<11$ PSU followed by a slight increase to $15 \mathrm{PSU}$ (Fig. 2a). In turn, temperature varied from an average of $4.9^{\circ} \mathrm{C}$ in February-March to $17.2^{\circ} \mathrm{C}$ in mid-August. During most of the investigation period the water column was thermally weakly stratified except during a short period from July to August, where a stronger thermocline was detected, as indicated by the isotherm of $15^{\circ} \mathrm{C}$ (Fig. 2b). The main hydrographic changes are revealed by the $\mathrm{T}-\mathrm{S}$ diagram which shows two main periods of vertical homogeneity related to cold and saltier waters during autumn and winter, and to warm and less saline waters during late spring-summer (Fig. 2c).

Plankton annual cycle

The spring bloom of phytoplankton started in May consisting mainly of the diatom Skeletonema 

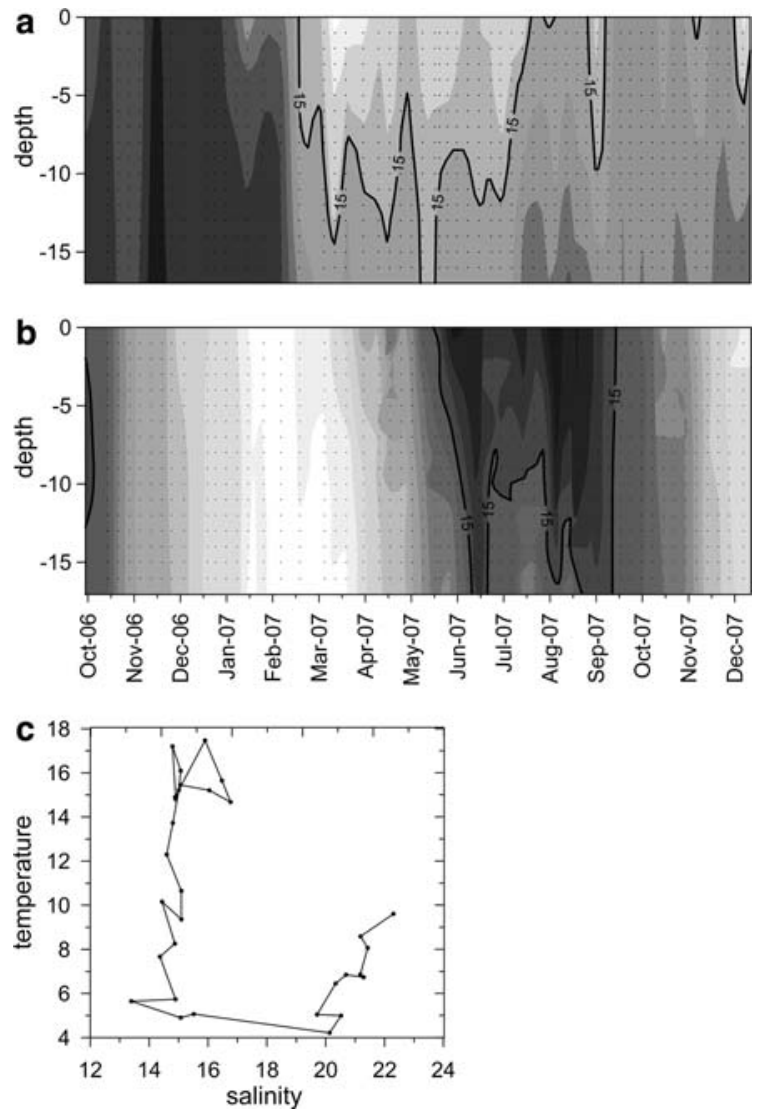

Fig. 2 Annual cycle of the hydrographic structure in Kiel Fjord. (a) Salinity, (b) temperature. Solid lines indicate the seasonal variability of 15 isohaline and $15^{\circ} \mathrm{C}$ isotherm. (c) T-S diagram of the period investigated illustrates two different hydrological periods of low salinity-high temperature (summer) and high salinity-low temperature (winter)

costatum (up to $99 \%$ of total abundance), followed by Thalassiosira spp. which dominated the post-bloom period, from late June to middle July (Fig. 3a). The first peak of zooplankton dominated by copepodite stages of the complex Para-Pseudocalanus occurred in December 2006. Copepods were by far the most abundant taxon of the mesozooplankton community throughout the year accounting for more than $50 \%$ of the total abundance of mesozooplankton. Cirriped and polycheate larvae ranked second (22\%) and third $(18 \%)$ in relative abundance, respectively (Fig. 3b). Fish larvae and eggs were observed for the first time in the middle of January, although their peak occurred from mid-June to mid-July (Fig. 3c) which was dominated by Clupeidae $(79.55 \%)$ and followed by Gobiidae (17.37\%). Gelatinous carnivores peaked

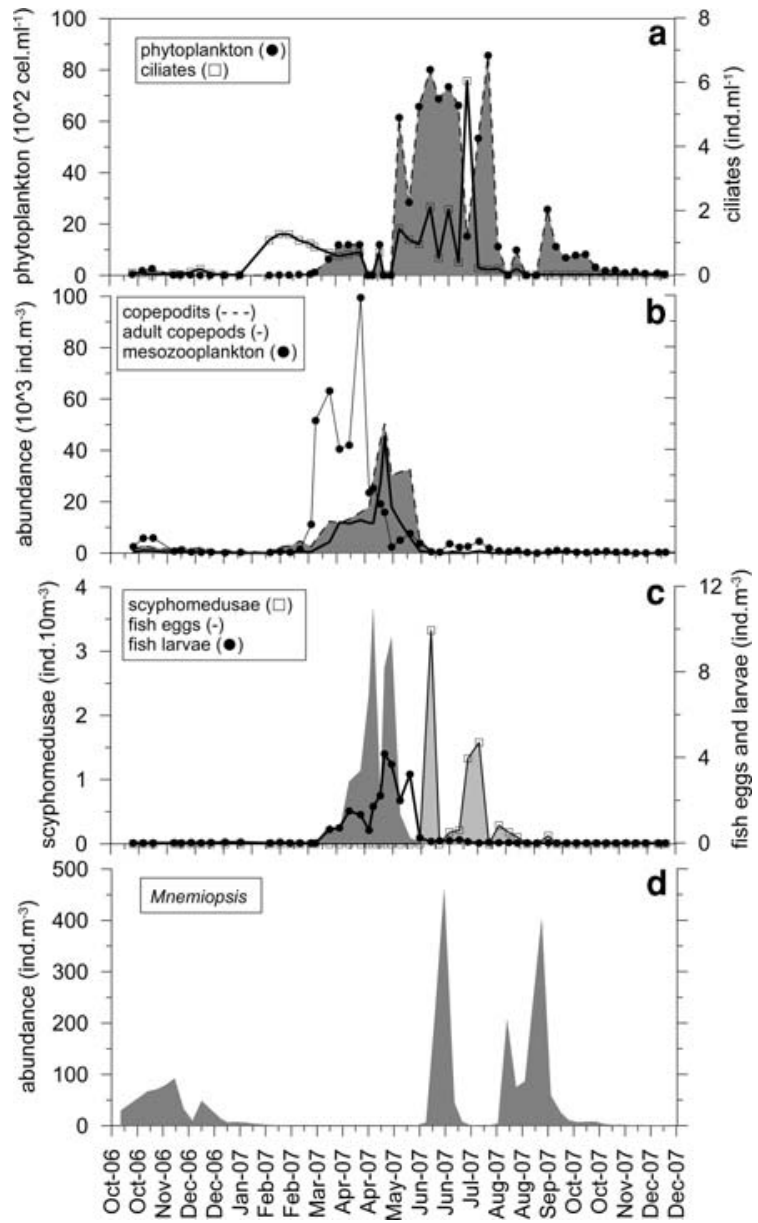

Fig. 3 Annual cycle of plankton communities' succession in Kiel Fjord. (a) Microplankton, (b) mesozooplankton, (c) ichthyioplankton and matured scyphomedusae and (d) Mnemiopsis leidyi

later and were mainly composed of Aurelia aurita and Cyanea capillata. Their abundance was however low $\left(<4\right.$ ind $\left.10 \mathrm{~m}^{-3}\right)$.

\section{Seasonal changes of Mnemiopsis leidyi}

During the study period, M. leidyi was always present. The population however showed marked fluctuations on short-time scales that ranged from 6 to 166 ind $\mathrm{m}^{-3}$ within 1 week. After the first record in the Kiel Fjord in October 2006 at densities of $\sim 30$ ind $\mathrm{m}^{-3}$, the population density of M. leidyi increased to a peak of ca. 100 ind $\mathrm{m}^{-3}$ which was followed by a sharp decrease to 1 ind $\mathrm{m}^{-3}$ during the wintertime (Fig. 3d). Its abundances remained low 
until June 2008. From August 2007 onwards M. leidyi reached the highest densities being $>5$-fold higher $\left(505\right.$ ind $\mathrm{m}^{-3}$ ) than the densities observed in the 2006 (Fig. 3d). During most of the sampling period approximately $85-90 \%$ of the population consisted of small larvae and post larvae of $<10 \mathrm{~mm}$. However, during its first occurrence and during late summer and autumn 2007 larger size classes were also common. The largest individual captured was one specimen with $60 \mathrm{~mm}$ total length, whereas the mean value of all adult specimens averaged $20 \pm 0.3 \mathrm{~mm}$.

The cumulative abundances increased markedly toward high percentiles in narrow ranges of temperature $\left(14-16^{\circ} \mathrm{C}\right)$ and salinity $(15-16)$, which were related to the summer period (Fig. 4). The temperature-salinity-M. leidyi diagram (Fig. 5) displays the narrow environmental space where the species reached the highest densities and emphasize the magnitude of the outburst the species may reach in the Kiel Fjord in short time scales.

Age structure and seasonal changes in the vertical distribution of M. leidyi

The age structure showed a marked seasonal pattern characterized by an alternation of periods dominated by larval stages followed by an increase of the proportion of adults (Fig. 6) emphasizing the recruitment dynamics of M. leidyi in the Kiel Fjord. In accordance with the temporal trend of the age structure, the vertical distribution of the species followed the same trend $(r=0.6 ; P<0.05)$ and exhibited marked seasonal changes. During winter and spring, when the species showed low densities and a high proportion of adults were present, the bulk of the population was concentrated in bottom waters. Afterwards, with the rising temperatures and the slight development of the vertical stratification, the population growth was dominated by a higher proportion of larval stages, and the bulk of the population shifted toward the upper layers (Fig. 6).

\section{Discussion}

We have shown the plankton annual cycle in the Kiel Fjord after the first report of M. leidyi occurrence. The weekly monitoring of plankton communities allowed us to recognize the timing of the first
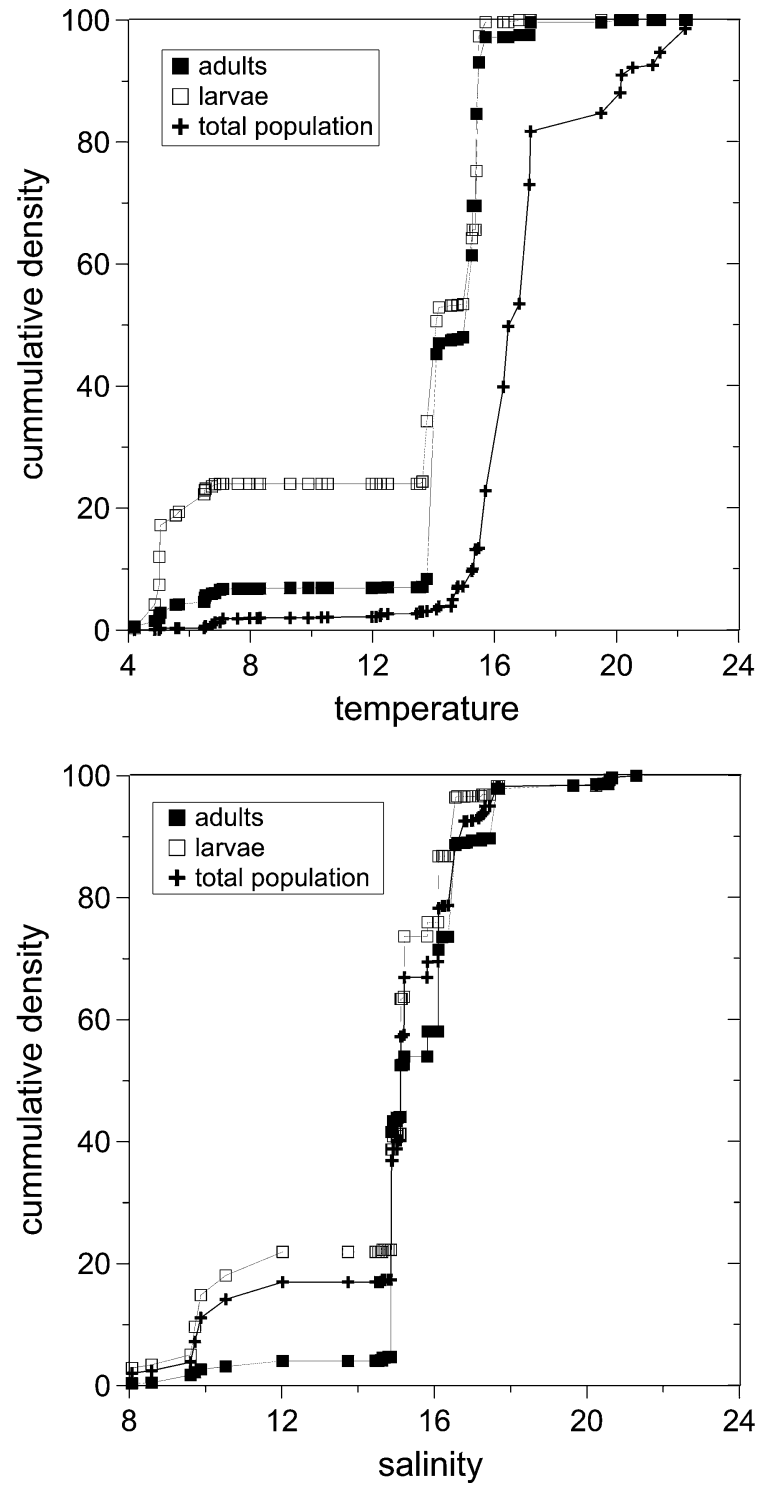

Fig. 4 Cumulative density of Mnemiopsis leidyi responding to temperature (upper panel) and salinity (lower panel). Note that temperature of $15^{\circ} \mathrm{C}$ and salinity of $15 \%$ triggered the population outburst of $M$. leidyi

observation of the invader M. leidyi in the southwestern Baltic Sea. After one year since its first record in this area, it has become clear that M. leidyi can successfully reproduce in the Kiel Fjord and possibly the entire Baltic Sea, as suggested by the seasonal changes in the ratio of larval stages:adults. M. leidyi is now established in the Baltic Sea as indicated in recent studies on the presence of the species in other sites of this area (Table 1). The potential predatory impact of this species in the 


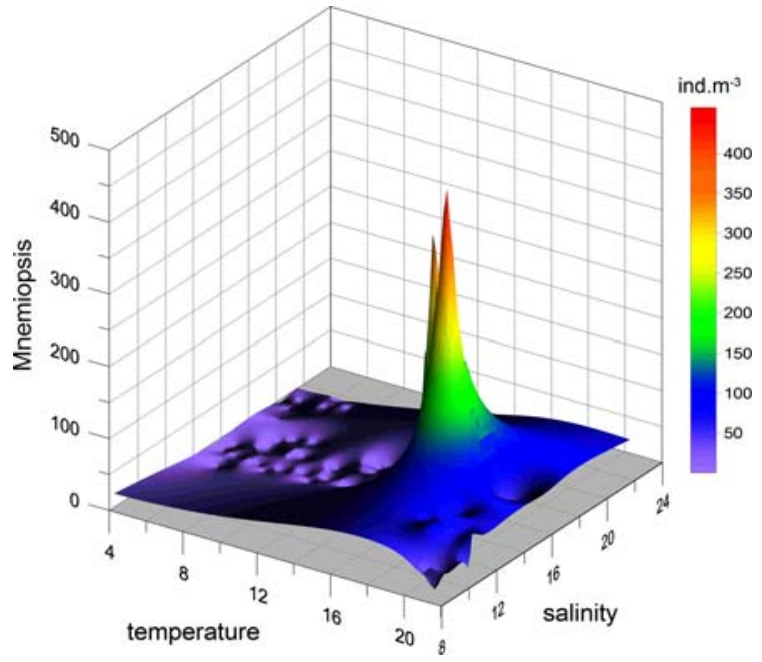

Fig. 5 3D graph of Mnemiopsis leidyi abundance-temperature-salinity. M. leidyi reaches its highest density in a narrow environmental space (between $14-17^{\circ} \mathrm{C}$ and salinity of $16-20$ ) that mainly corresponds to summer season
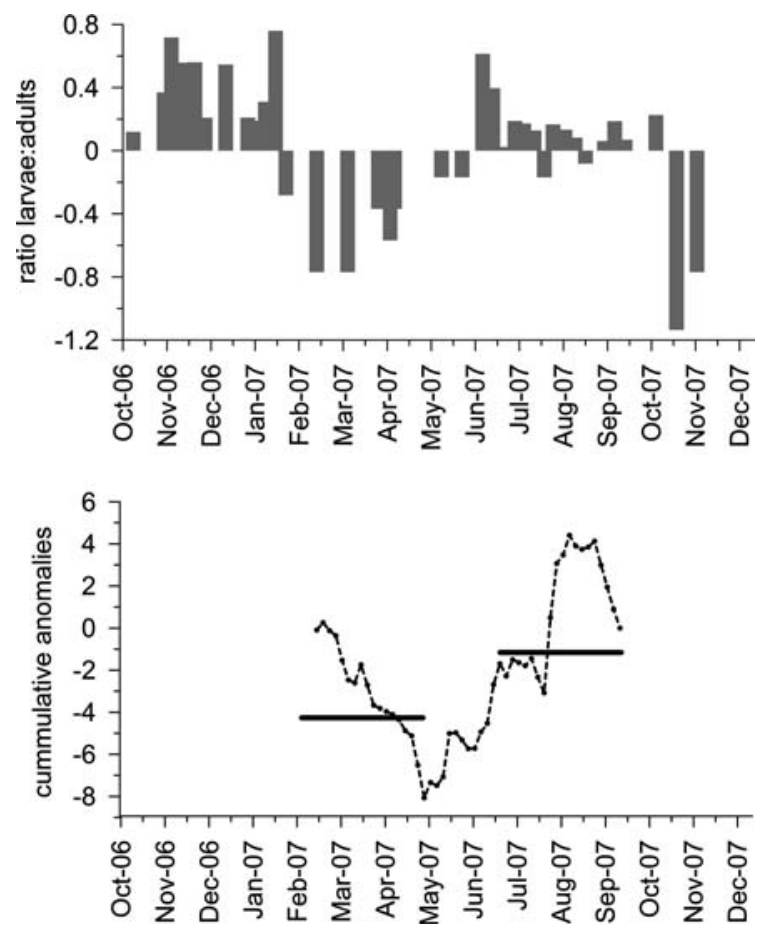

Fig. 6 Temporal variation in ratio larvae:adults (upper panel) and cumulative anomalies of the vertical distribution of Mnemiopsis leidyi (bottom panel). Horizontal bars indicate the mean abundance during the two main periods related to the vertical distribution of the species. The downward trend indicates the predominance of the population located in bottom layers and the upward trend indicates the shift of the vertical distribution to upper layers starting in May pelagic ecosystem makes the recent range of expansion a matter of concern.

Hydrographic features in the water balance of the Kiel Fjord are mainly driven by the baroclinic forcing of the Kiel Bight. The mean flushing time in the fjord has been calculated to be about 45 days but can be shorter during winter. Under strong wind conditions the Kiel Fjord can completely be flushed within a few days (Fig. 2a: Nov.-Dec. 2006 and Feb.-Mar. 2007, Lehmann personal communication).

In this framework, the annual cycle of mesozooplankton in the Kiel Fjord followed the recurrent pattern of temperate pelagic ecosystems. After a minor bloom of phytoplankton in March, the main spring bloom started in May 2007. The peak of fish larvae matched with the maximum abundances of mesozooplankton, suggesting a predator-prey interaction with fish larvae controlling the drop of mesozooplankton. Gelatinous carnivores peaked later and matched with the peaks of phytoplankton and ciliates. The general annual cycle of the pelagic system of the Kiel Bight is basically similar to the gained data of ours with the diatom spring bloom, the late spring copepod maximum and the summer stratification (Smetacek 1983).

It is worth noting that $M$. leidyi has been the only ctenophore observed from late summer 2006 onwards. Previous to its invasion, the ctenophore Pleurobrachia pileus was common during wintertime in the Kiel Bight. In recent decades Baltic Sea has faced hydrological changes which were driven by global warming (Lehmann and Hinrichsen 2000). As $P$. pileus population of the Baltic Sea shows a preference for cold water (Schneider 1987) it is possible that the recent environmental changes reported in the hydrographic properties of the Baltic Sea (i.e. warm temperatures), have impaired the development of $P$. pileus. This should be however verified by getting longer data sets.

Population dynamics and vertical distribution

The one year data reported here allowed us tracking general features of the M. leidyi population dynamics in the Kiel Fjord. The annual abundance of M. leidyi is similar to the annual pattern of populations distributed in its northern native habitat and in the exotic habitat of the Black Sea and the Caspian Sea (Purcell et al. 2001; Finenko et al. 2006a; Finenko 
Table 1 Baltic Sea locations where Mnemiopsis leidyi has been recorded after the first appearance in the Kiel Fjord

\begin{tabular}{|c|c|c|c|c|c|c|c|}
\hline Location & $\begin{array}{l}\text { Period of } \\
\text { observation }\end{array}$ & $\begin{array}{l}\text { Maximum } \\
\text { abundance } \\
\text { (ind } \mathrm{m}^{-3} \text { ) }\end{array}$ & $\begin{array}{l}\text { Size } \\
(\mathrm{cm})\end{array}$ & $\begin{array}{l}\text { Mesh } \\
\text { size } \\
(\mu \mathrm{m})\end{array}$ & $\mathrm{T}\left({ }^{\circ} \mathrm{C}\right)$ & S (\%o) & Reference \\
\hline Central Baltic Sea & Jan.-May 2007 & $<4$ & $<0.5$ & WP2, 400 & $3-14$ & $18-11$ & Kube et al. (2007) \\
\hline Bornholm Basin & Aug. 2007 & 0.4 & NA & $\begin{array}{c}\text { Bongo, } 335 \\
\text { and } 500\end{array}$ & $4-8$ & $11-16$ & Haslob et al. (2007) \\
\hline Gulf of Gdansk & Oct.-Nov. 2007 & $3-20$ & $1.8-8$ & Divers, NA & $6-14$ & NA & Janas and Zgrundo (2007) \\
\hline Gulf of Finland & Aug. 2007 & 24 & 15 & $\begin{array}{r}\text { WP2, } 500 \\
\text { and } 100\end{array}$ & $4.5-5$ & $6.5-9$ & Lehtiniemi et al. (2007) \\
\hline Limfjorden & Sep. 2007 & 629 & $\begin{array}{r}0.5- \\
15\end{array}$ & $\begin{array}{l}\text { Plankton net, } \\
2000\end{array}$ & 15 & $27-28.5$ & Riisgård et al. (2007) \\
\hline Little Belt & Feb. and May-Sep. 2007 & NA & $<12$ & Divers, NA & NA & NA & Tendal et al. (2007) \\
\hline
\end{tabular}

The maximal abundances reported, size of individuals, plankton net used, as well as the hydrographic conditions are indicated NA, not available

et al. 2006b) where the annual cycle is characterized by a main peak in late summer-early autumn. Moreover, the seasonal pattern of the population of M. leidyi shows marked changes in the relative abundance of larval stages and adults, which were accompanied by changes in the dominant size classes. The pattern suggests two periods of high reproduction activity associated to warmer temperatures, i.e. early autumn 2006 and late summer 2007, and one main period of low reproductive activity associated to the lowest temperatures and the low population density (Fig. 6). It is worth noting that the maximum abundances of $M$. leidyi did not match with the peaks of mesozooplankton and fish larvae. Instead it appears coupled with the peak of microzooplankton, suggesting a primary predation on microzooplankton (i.e. ciliates) by the high density of larval stages. It is known that gelatinous carnivores are able to exploit microplankton communities, including the microbial food web and prey on ciliates, which have proven a nitrogen-rich food source (Gifford 1991). Although M. leidyi has been traditionally considered as strictly carnivore, empirical investigations have shown that all size classes of $M$. leidyi larvae and postlarvae consumed nano- and microplankton in excess of their minimum food requirement, which may represent a main nitrogen source for population growth (Sullivan and Gifford 2004). This can have important ecological implications since by exerting high predation pressures on ciliates a potential impact on the structure of microzooplankton assemblages may favour in some cases the formation of red tides, as shown by Pitt et al. (2007) in mesocosms experiments. Moreover, we cannot exclude cannibalism and predation on other gelatinous zooplankton, as suggested by the high concentrations of jellyfish planula larvae in the gut content of M. leidyi in summer (Javid Pour, personal observation).

The assessment of the vertical distribution during the period March-December 2007 allowed detecting two contrasting situations, low and high abundances, where the vertical population structure changed markedly. While during the low abundance period (March-June) the bulk of the population was concentrated in deep layers, during the outburst of the species (August-September) the vertical pattern shifted and the bulk of the population was located in the upper layers. Dense aggregation of the M. leidyi in deep layers are likely a population response to low temperatures, which have been found to constrain the reproductive potential and as an energy saving strategy of ctenophores (Esser et al. 2004). The shift in the vertical pattern from bottom to upper layers matched with the temperature increase in late spring, which enhances the reproduction capacities of the species and allows a fast expansion in the water column. The benefits of such strategy may provide a refuge to $M$. leidyi to avoid flushing in upper layers, and subsequently provide inocula for late-spring population growth. Support to this interpretation has been given by Costello et al. (2006) who showed that during winter months and low population densities $M$. leidyi concentrate in coastal areas that provide refuge and play an important role 
as population source for the summer population growth. As shown by these authors, such a pattern is common in the M. leidyi populations inhabiting temperate regions with cold winters.

The life history traits of $M$. leidyi allow the species to be highly responsive to environmental opportunities. As we have shown here, within favorable environmental conditions the species may double its population size within a few days. Owing to the potential impacts of this ctenophore on the pelagic food web, their abundance variations over the interannual scale may then constitute valuable ecosystem state indicators.

Consequences for the ecosystem function

Jellyfish are now recognized as critical indicators and drivers of ecosystem performance and change (Molinero et al. 2005; Hay 2006; Lynam et al. 2006). Jellyfish mass developments in several coastal areas may allow ecosystem shifts from fish dominance to dominance of gelatinous carnivores, which have been found generally irreversible, as jellyfish may control fish eggs and larvae and compete with fish for food (Lynam et al. 2006). Since these voracious predators may channel flows of energy and matter away from the economically important food chain algae-copepods-fish (Sommer et al. 2002; Stibor and Tokle 2003), the integration of jellyfish understanding and data becomes a critical component of an ecosystem approach to fishery management increasingly critical (Lynam et al. 2005). In the particular case of the Baltic Sea it is not yet clear whether M. leidyi can severely affect zooplankton and fish populations through its feeding on fish larvae and eggs or competition for food. However, owing to the expected increase in water temperatures in the next decade of the Baltic Sea and the remarkable ability of this invader to double its population size in short time periods, it is definitely a matter for current concern and a critical challenge in predicting future risks of the Baltic Sea ecosystem development. In addition, in the global warming framework, synergism between marine invaders, overfishing and climate change may have drastic consequences in the functioning of the Baltic Sea pelagic ecosystem. M. leidyi is now established in the Baltic Sea but the spread in the basin as well as the consequences in the food-web constitute a current challenge in the ecology of the
Baltic Sea. Future research should deal with the identification of hot-spot areas which may potentially act as refuge during low population densities, as well as Allee effects and invasion risks in global warming scenarios. In fact, adequate risk analysis of biological invasion cannot neglect these considerations. Owing to the key role of M. leidyi in coastal ecosystems biological oceanographers and resource managers in the Baltic Sea cannot afford to ignore this invasive species. In this framework, the results here presented can be considered as baseline for future research on M. leidyi and its potential effects in the Baltic Sea.

Acknowledgments We thank the crew of the vessel Polarfuchs, and master students for their help to collect materials. We are grateful to Andreas Lehmann, Frank Sommer and Catriona Clemmensen for their valuable comments on the manuscript. Our work was financially supported by the Landesamt für Natur und Umwelt des Landes Schleswig-Holstein and IFM-GEOMAR interdisciplinary project.

Open Access This article is distributed under the terms of the Creative Commons Attribution Noncommercial License which permits any noncommercial use, distribution, and reproduction in any medium, provided the original author(s) and source are credited.

\section{References}

Alheit J, Mollmann C, Dutz J, Kornilovs G, Loewe P, Mohrholz V et al (2005) Synchronous ecological regime shifts in the central Baltic and the North Sea in the late 1980s. ICES J Mar Sci 62:1205-1215. doi:10.1016/j.icesjms. 2005.04.024

Bilio M, Niermann U (2004) Is the comb jelly really to blame for it all? Mnemiopsis leidyi and the ecological concerns about the Caspian Sea. Mar Ecol Prog Ser 269:173-183. doi: $10.3354 /$ meps 269173

Costello JH, Sullivan BK, Gifford DJ, Van Keuren D, Sullivan LJ (2006) Seasonal refugia, shoreward thermal amplification, and metapopulation dynamics of the ctenophore Mnemiopsis leidyi in Narragansett Bay, Rhode Island. Limnol Oceanogr 51:1819-1831

Escribano R, Hidalgo P (2000) Spatial distribution of copepods in the north of the Humboldt Current region off Chile during coastal upwelling. J Mar Biol Assoc UK 80:283290. doi:10.1017/S002531549900185X

Esser M, Greve W, Boersma M (2004) Effects of temperature and the presence of benthic predators on the vertical distribution of the ctenophore Pleurobrachia pileus. Mar Biol (Berl) 145:595-601. doi:10.1007/s00227-004-1348-0

Faasse MA, Bayha KM (2006) The ctenophore Mnemiopsis leidyi A. Agassiz 1865 in coastal waters of the Netherlands: an unrecognized invasion? Aquat Invasions 1: 270-277 
Finenko GA, Kideys AE, Anninsky BE, Shiganova TA, Roohi A, Tabari MR et al (2006a) Invasive ctenophore Mnemiopsis leidyi in the Caspian Sea: feeding, respiration, reproduction and predatory impact on the zooplankton community. Mar Ecol Prog Ser 314:171-185. doi: 10.3354/meps314171

Finenko GA, Romanova ZA, Abolmasova GI, Anninsky BE, Pavlovskaya TV, Bat L et al (2006b) Ctenophores invaders and their role in the trophic dynamics of the planktonic community in the coastal regions off the Crimean coasts of the Black Sea (Sevastopol Bay). Oceanology (Mosc) 46:472-482

Gifford DJ (1991) The Protozoan-Metazoan trophic link in pelagic ecosystems. J Eukaryot Microbiol 38:81-86. doi: 10.1111/j.1550-7408.1991.tb04806.x

Gollasch S, Leppäkoski E (2007) Risk assessment and management scenarios for ballast water mediated species introductions into the Baltic Sea. Aquat Invasions 2:313340. doi:10.3391/ai.2007.2.4.3

Haslob H, Clemmesen C, Schaber M, Hinrichsen HH, Schmidt JO, Voss R et al (2007) Invading Mnemiopsis leidyi as a potential threat to Baltic fish. Mar Ecol Prog Ser 349:303306. doi:10.3354/meps07283

Hay S (2006) Marine ecology: gelatinous bells may ring change in marine ecosystems. Curr Biol 16:679-682. doi: 10.1016/j.cub.2006.08.010

Huntley M, Escritor F (1991) Dynamics of Calaniodes acutus (copepda, calanoida) in Antarctic coastal waters. Deep Sea Res Part I Oceanogr Res Pap 38:1145-1167. doi: 10.1016/0198-0149(91)90100-T

IPCC (2007) Climate change 2007: the physical science basis. Contribution of working group I to the fourth assessment report of the intergovernmental panel on climate change. In Solomon S, Qin D, Manning M, Chen Z, Marquis M, Averyt KB, Tignor M, Miller HL (eds) Cambridge University Press, Cambridge, 996 pp

Janas U, Zgrundo A (2007) First record of Mnemiopsis leidyi A. Agassiz 1865 in the Gulf of Gdańsk (southern Baltic Sea). Aquat Invasions 2:450-454. doi:10.3391/ai.2007.2.4.18

Javidpour J, Sommer U, Shiganova TA (2006) First record of Mnemiopsis leidyi A. Agassiz 1865 in the Baltic Sea. Aquat Invasions 1:299-302

Kube S, Postel L, Honnef C, Augustin CB (2007) Mnemiopsis leidyi in the Baltic Sea-distribution and overwintering between autumn 2006 and spring 2007. Aquat Invasions 2:137-145

Lehmann A, Hinrichsen HH (2000) On the wind driven and thermohaline circulation of the Baltic Sea. Phys Chem Earth, Part B Hydrol Oceans Atmos 25:183-189. doi: 10.1016/S1464-1909(99)00140-9

Lehtiniemi M, Pääkkönen J-P, Flinkman J, Katajisto T, Gorokhova E, Karjalainen M, Viitasalo S, Björk H (2007) Distribution and abundance of the American comb jelly (Mnemiopsis leidyi) — a rapid invasion to the northern Baltic Sea during 2007. Aquat Invasions 2:445-449. doi: 10.3391/ai.2007.2.4.17

Leppakoski E, Gollasch S, Gruszka P, Ojaveer H, Olenin S, Panov V (2002) The Baltic-a sea of invaders. Can J Fish Aquat Sci 59:1175-1188. doi:10.1139/f02-089

Levine JM (2008) Biological invasions. Curr Biol 18:57-60. doi:10.1016/j.cub.2007.11.030
Lynam CP, Gibbons MJ, Axelsen BE, Sparks CAJ, Coetzee J, Heywood BG et al (2006) Jellyfish overtake fish in a heavily fished ecosystem. Curr Biol 16:R492-R493. doi: 10.1016/j.cub.2006.06.018

Lynam CP, Hay SJ, Brierley AS (2005) Jellyfish abundance and climatic variation: contrasting responses in oceanographically distinct regions of the North Sea, and possible implications for fisheries. J Mar Biol Assoc UK 85:435450. doi:10.1017/S0025315405011380

Molinero JC, Ibanez F, Nival P, Buecher E, Souissi S (2005) North Atlantic climate and northwestern Mediterranean plankton variability. Limnol Oceanogr 50:1213-1220

Occhipinti-Ambrogi A, Savini D (2003) Biological invasions as a component of global change in stressed marine ecosystems. Mar Pollut Bull 46:542-551. doi:10.1016/ S0025-326X(02)00363-6

Oguz T, Gilbert D (2007) Abrupt transitions of the top-down controlled Black Sea pelagic ecosystem during 19602000: evidence for regime-shifts under strong fishery exploitation and nutrient enrichment modulated by climate-induced variations. Deep Sea Res Part I Oceanogr Res Pap 54:220-242. doi:10.1016/j.dsr.2006.09.010

Österblom H, Hansson S, Larsson U, Hjerne O, Wulff F, Elmgren R et al (2007) Human-induced trophic cascades and ecological regime shifts in the Baltic Sea. Ecosystems (NY, Print) 10:877-889. doi:10.1007/s10021-007-9069-0

Paavola M, Olenin S, Leppakoski E (2005) Are invasive species most successful in habitats of low native species richness across European brackish water seas? Estuar Coast Shelf Sci 64:738-750. doi:10.1016/j.ecss.2005. 03.021

Paramo J, Quinones RA, Ramirez A, Wiff R (2003) Relationship between abundance of small pelagic fishes and environmental factors in the Colombian Caribbean Sea: an analysis based on hydroacoustic information. Aquat Living Resour 16:239-245. doi:10.1016/S0990-7440(03) 00043-3

Perry RI, Smith SJ (1994) Identifying habitat associations of marine fishes using survey data-an application to the northwest Atlantic. Can J Fish Aquat Sci 51:589-602

Pitt KA, Kingsford MJ, Rissik D, Koop K (2007) Jellyfish modify the response of planktonic assemblages to nutrient pulses. Mar Ecol Prog Ser 351:1-13

Purcell JE, Shiganova TA, Decker MB, Houde ED (2001) The ctenophore Mnemiopsis leidyi in native and exotic habitats: US estuaries versus the Black Sea basin. Hydrobiologia 451:145-176. doi:10.1023/A:1011826618539

Riisgård HU, Bøttiger L, Madsen CV, Purcell JE (2007) Invasive ctenophore Mnemiopsis leidyi in Limfjorden (Denmark) in late summer 2007-assessment of abundance and predation effects. Aquat Invasions 2:395-401. doi:10.3391/ai.2007.2.4.8

Schneider G (1987) Role of advection in the distribution and abundance of Pleurobrachia pileus in Kiel Bight. Mar Ecol Prog Ser 41:99-102. doi:10.3354/meps041099

Shiganova TA (1998) Invasion of the Black Sea by the ctenophore Mnemiopsis leidyi and recent changes in pelagic community structure. Fish Oceanogr 7:305-310. doi:10.1046/j.1365-2419.1998.00080.x

Shiganova TA, Mirzoyan ZA, Studenikina EA, Volovik SP, Siokou-Frangou I, Zervoudaki S et al (2001) Population 
development of the invader ctenophore Mnemiopsis lei$d y i$, in the Black Sea and in other seas of the Mediterranean basin. Mar Biol (Berl) 139:431-445. doi: $10.1007 / \mathrm{s} 002270100554$

Smetacek V (1983) The annual cycle of Kiel Bight planktona long term analysis. Estuaries 6:328-328

Sommer U, Stibor H, Katechakis A, Sommer F, Hansen T (2002) Pelagic food web configurations at different levels of nutrient richness and their implications for the ratio fish production: primary production. Hydrobiologia 484:1120. doi:10.1023/A:1021340601986

Stibor H, Tokle N (2003) Feeding and asexual reproduction of the jellyfish Sarsia gemmifera in response to resource enrichment. Oecologia 135:202-208
Stone R (2005) Science in Iran-an Islamic science revolution? Science 309:1802-1804. doi:10.1126/science.309. 5742.1802

Sullivan LJ, Gifford DJ (2004) Diet of the larval ctenophore Mnemiopsis leidyi A. Agassiz (Ctenophora, Lobata). J Plankton Res 26:417-431. doi:10.1093/plankt/fbh033

Tendal OS, Jensen KR, Riisgård HU (2007) Invasive ctenophore Mnemiopsis leidyi widely distributed in Danish waters. Aquat Invasions 2:455-460 